\title{
EXPERIÊNCIA FOTOETNOGRÁFICA: ENTRE A ESCRITA IMAGÉTICA E AS IMAGENS PARAFRASEADAS
}

Priscila Gayer ${ }^{1}$

\section{Introdução}

A discussão aqui apresentada retrata a experiência teórica e prática da fotoetnografia integrante da pesquisa Mediações culturais e a experiência turística no espaço urbano: formalidades do olhar turístico sobre a cidade de Buenos Aires, a qual buscava compreender em que medida as representações sociais de Atrativo Turístico influenciavam na construção de sentidos sobre Buenos Aires tanto por aqueles que a produziam enquanto uma cidade turística, quanto pelos turistas que a vivenciavam de diferentes formas. A pesquisa contou com o método de Análise de Discurso e logo após foi feita uma fotoetnografia da categoria de análise Atratividade, relacionada à complexidade do cotidiano que anima o espaço urbano, a qual faz um contraponto à categoria de Atrativo Turístico, conceito científico e do senso comum historicamente construído e sistematizado sob o prisma mercadológico como um conjunto simplista de elementos que representam aquilo que é de interesse do turista. A escolha pela fotoetnografia do espaço urbano e sua atratividade foi sustentada conforme argumentos aqui apresentados. Porém, nesse momento busco salientar a reverberação literal que sustentou cada disparo de abertura do obturador.

O ponto central da proposta é demonstrar que apesar de a Antropologia Visual trazer sim novos modos de problematizar a realidade e suas formas sensíveis por meio de outros recursos narrativos e de representação, a escrita encontra sua transgressão igualmente ao representar pensamentos imagéticos. As imagens produzidas cientificamente também estão envolvidas por um repertório conceitual desenvolvido basicamente por meio da escrita. Para iniciar, como exemplo, abaixo apresento os fluxos e fixos de Milton Santos (1997), bem como a múltipla temporalidade do espaço urbano. Aí apresentam-se duas categorias conceituais literal e amplamente discutidas: tempo e espaço.

\footnotetext{
${ }^{1}$ Fundação Universidade de Rio Grande, Brasil.
} 


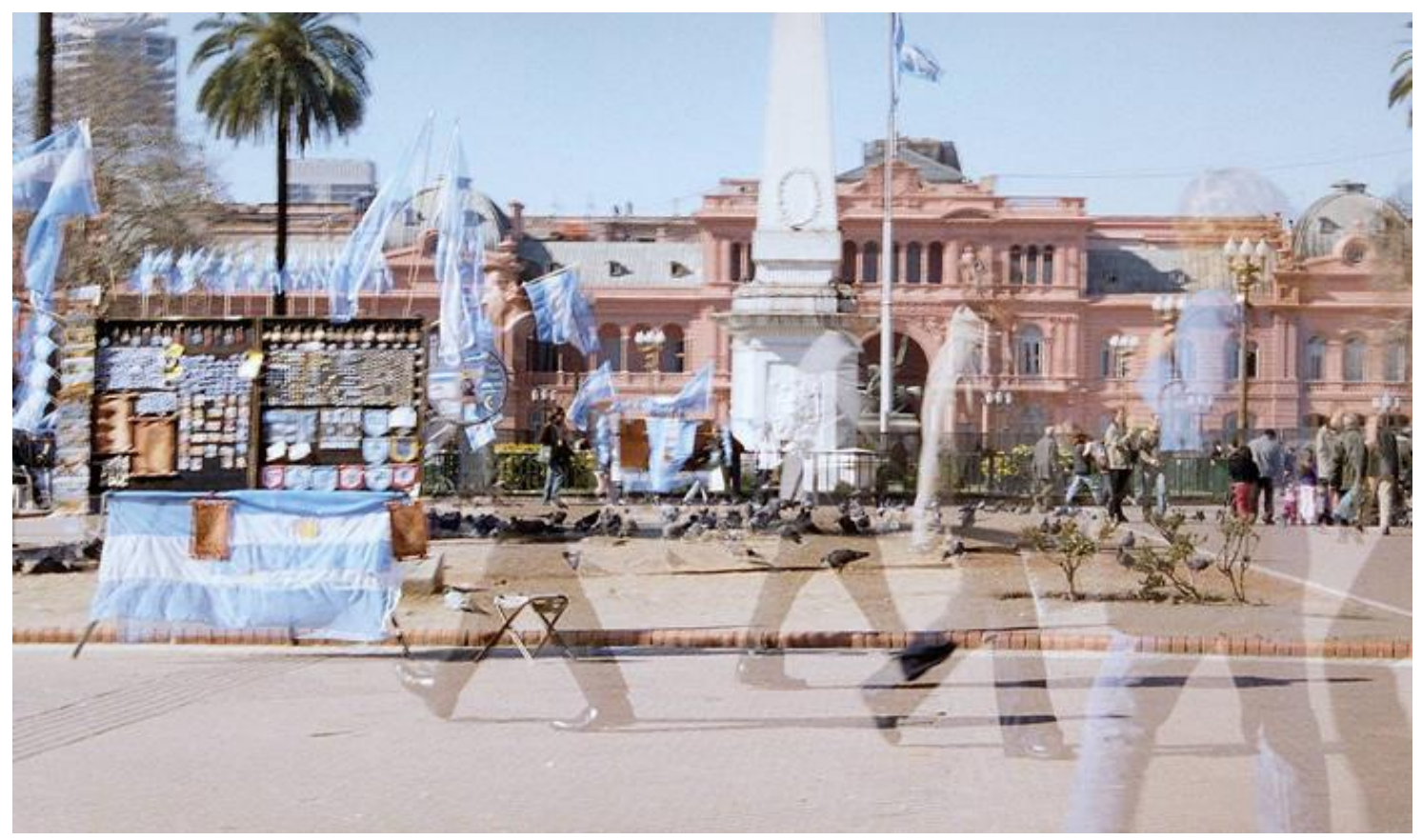

Evidencia-se assim o potencial narrativo das imagens, porém entra em foco a capacidade de interpretá-las por meio de uma necessária herança teórica ainda sustentada pela escrita. Igualmente vale ressaltar que o trabalho de campo está permeado não apenas pelo olhar do observador, do antropólogo, constituído por um conjunto verbal conceitual que o instiga e o orienta em cada recorte, mas também pela técnica. A imagem acima foi produzida por meio de uma câmera analógica e exigiu que a contagem da exposição fosse dividida em duas sobreposições de imagens, com duas aberturas do obturador. Para isso, foi necessário fotometrar, criar a harmonia entre diafragma e obturador, para poder então fazer a contagem da exposição corretamente. Além da técnica, a segurança pública também interfere. Nesse caso o tripé foi desconsiderado, sendo necessário muito fôlego para evitar as mãos trêmulas enquanto o tempo em segundos era contado mentalmente entre duas exposições de luz sobre uma mesma película.

\section{A construção visual de um conceito}

O aporte das imagens vem sendo utilizado com diferentes propósitos dentro da produção do conhecimento antropológico. Tendo em vista seu potencial de registro, para além da comprovação da realização da experiência antropológica do estar lá, imagens 
podem ser produzidas com a finalidade de registrar dados empíricos para análises posteriores ao trabalho de campo, podendo vir a ilustrar a representação etnográfica sobre o Outro quando construída tradicionalmente por meio da escrita. Ainda, a utilização de fotografias em campo pode ser uma ferramenta de produção partilhada do conhecimento etnográfico na medida em que os sujeitos pesquisados passam a refletir com o antropólogo sobre os sentidos daquelas imagens - o que foi chamado de modo reflexivo, indo além do caráter documentário ou de registro (Bittencourt, 1998). O aspecto documental das imagens acerca da cultura material pode ser explorado visando ao aprofundamento da compreensão do contexto histórico-sociocultural de uma dada sociedade através da análise do conteúdo dessas imagens - nesse âmbito, também utilizadas como fonte na história cultural (Bittencourt, 1998; Paiva, 2004). Ainda, considerando que a produção de imagens é orientada por mediações culturais específicas, as quais implicam em determinadas formas de ver e interpretar o real, as imagens produzidas por um grupo documentam, não apenas as formas sensíveis presentes em seu cotidiano, mas o seu peculiar olhar sobre o mundo. Desse modo, a análise dessas expressões imagéticas permite o desvelamento do universo cultural que as atravessa e que através delas é negociado, tornando-as inteligíveis - empreendimento analítico caracterizado por uma antropologia da imagem, o que vem a indicar algumas diferenciações em relação à Antropologia Visual.

\footnotetext{
Da forma como compreendemos, a antropologia visual não é uma "disciplina independente", nem mesmo de uma subárea, como a antropologia política ou uma antropologia do cinema. Trata-se, sim, da mesma e "velha" antropologia de sempre, mas apresentada sobre este outro continente que é a comunicação audiovisual. Não é uma antropologia da imagem, mas uma antropologia em imagens (Eckert; Godolphim; Rodolpho; Rosa, 1995, p. 244).
}

A Antropologia Visual provoca uma ruptura com a perspectiva de utilização da imagem até aqui apresentada, na qual as imagens são apropriadas como ilustração, objeto de análise ou enquanto registros dos dados empíricos coletados em campo a serem interpretados pelo pesquisador na construção da uma representação etnográfica ancorada na escrita. Verdade que as reflexões metodológicas e técnicas suscitadas pela Antropologia Visual vêm contribuindo para o aprimoramento da utilização da imagem em campo (Eckert; Godolphim; Rodolpho; Rosa, 1995). Todavia, a Antropologia Visual transcende essas questões ao explorar o potencial narrativo das imagens, trazendo 
perturbações epistemológicas e não se limitando a reflexões acerca do caráter documental (de registro) ou das demais inserções da imagem em campo orientadas por determinadas metodologias de interação.

Inicialmente poderíamos distinguir três objetivos gerais que justificariam o emprego de técnicas audiovisuais na pesquisa antropológica. Num primeiro momento ela aparece como uma forma de captação de dados, no segundo como uma meio que possibilita a comunicação-interação sujeito-objeto, e por fim como um instrumento de divulgação ao nível didático-acadêmico e/ou social (Eckert; Godolphim; Rodolpho; Rosa; 1995, p. 244).

There is, on the one hand, the visual anthropology that studies visible cultural forms. On the other is the visual anthropology that uses the visual media to describe and analyze culture. [...] The two will sometimes overlap - the study of visible systems sometimes demands visual communication - but the first form is essentially an extension of traditional anthropological concerns into new subject areas. The second proposes a much more radical break with anthropological modes of discourse (Macdougall, 2006, p. 217) ${ }^{2}$.

Quando o potencial narrativo das imagens é apropriado para a construção e divulgação do conhecimento antropológico, a imagem passa a ser constitutiva da representação etnográfica. Portanto, diante da evidente possibilidade de suportes narrativos $^{3}$ alternativos, a Antropologia Visual traz inquietações epistemológicas à sua disciplina como um todo. Reiterando, propor novas bases narrativas culmina na ampliação do leque das formas expressivas sobre as quais a produção do conhecimento antropológico pode ser alicerçada, subvertendo a legitimidade científica hegemônica da escrita. Essas inquietações permeiam os campos epistemológico, metodológico e técnico:

The case of visual anthropology is especially interesting. The particular nature of the synthesis pursued resulted in the exposure of issues about epistemology (science), method (observation) and form (writing) which were central, if largely unacknowledged, to modern anthropology itself (Grimshaw, 2003, p. 86) ${ }^{4}$.

2 Há, por um lado, a antropologia visual que estuda formas culturais visíveis. Por outro lado, há a antropologia visual que usa o aporte da mídia visual para descrever e analisar as culturas. [...] as duas, em algum momento, vão se sobrepor - o estudo de sistemas visuais, por vezes, demanda comunicação visual - mas a primeira forma é essencialmente uma extensão dos problemas da antropologia tradicional em novas áreas. A segundo propõe uma ruptura mais radical nos moldes do discurso antropológico [tradução].

3 A imagem de modo amplo e o som, assim como suas diferentes articulações - o audiovisual e o hipertexto, por exemplo.

${ }^{4} \mathrm{O}$ caso da antropologia visual é especialmente interessante. A particularidade da síntese procurada resultou na exposição de questões sobre epistemologia (ciência), método (observação) e forma (escrita) que eram centrais, senão desconhecidas em grande parte, para a própria antropologia moderna [tradução]. 
No campo da epistemologia, a Antropologia Visual problematiza questões acerca da cientificidade do conhecimento antropológico, no que tange a sua objetividade e subjetividade, e ao repensar diferentes formas de conhecer acaba por trazer a tona instâncias que, até então, não eram passíveis de problematização adequada dentro dos limites da narrativa escrita. Isto porque "a linguagem escrita e a linguagem visual são linguagens diferentes que fornecem informações diferentes e que exigem do leitor operações mentais também diferentes" (Achutti, 2000). Nesse sentido, MacDougall afirma que a Antropologia Visual "may offer different ways of understanding, but also different thing to understand" (2006, p. 220) ${ }^{5}$. Logo, a Antropologia Visual representa uma ruptura com a narrativa escrita - distanciamento que não implica na supressão do texto escrito - e mais: (re)posiciona o foco investigativo sobre outros aspectos da vida social. Por conseguinte, exigindo um corpo teórico próprio para o tratamento desse universo simbólico expresso nas formas sensíveis da vida, agora postas em análise, sendo necessário ir além da simples adequação dos conceitos pré-existentes da antropologia tradicional.

O mais possível é que antropologia visual progressivamente se volte para o estudo de aspectos da realidade social, incluindo os tópicos previamente ignorados. Fora o fato de que alguns fenômenos sociais são mais bem estudados por meio do audiovisual (por exemplo, como determinadas poses detém emoções), os mesmo dificilmente podem ser abordados de alguma outra forma. Assim, a antropologia visual está emergindo como um tipo diferente de antropologia e não como substituta da antropologia escrita (Macdougall, 2005, p. 24).

Apenas para complementar o pensamento de MacDougall, diz o pesquisador em outro espaço de reflexão: "visual anthropology can never be either a copy of written anthropology or a substitute for it. For that very reason it must develop alternative objectives and methodologies that will benefit anthropology as a whole" (Macdougall, 2006, p. 225$)^{6}$.

No que tange ao conteúdo e ao objeto de estudo, essa antropologia através das imagens privilegia o enfoque das formas sensíveis da vida, os detalhes simbólicos que transcendem a capacidade representacional da escrita como, por exemplo, as

\footnotetext{
5 Pode oferecer diferentes formas de compreensão, mas igualmente diferentes questões a serem compreendidas [tradução].

6 A Antropologia visual jamais deve ser vista como uma cópia da antropologia escrita visual, menos como substituta dessa última. Por esse motivo, deve-se desenvolver objetos e metodologias alternativas que venham a beneficiar a antropologia como um todo [tradução].
} 
expressões, os gestos, os sentimentos que esses expressam, as relações dos corpos e dos objetos no espaço, as peculiaridades dos trajes e o que o seu conjunto simboliza. O que remete a uma outra postura de investigação: "além do modo próprio por meio do qual o meio visual se dirige ao seu público, nosso trabalho se concentraria na inter-relação dos objetos, pessoas, tempo e lugar em vez de abstrações sociais mais amplas" (Macdougall, 2005, p. 26).

Diante dessa conjuntura, Mirian Moreira Leite chama atenção dos novos pesquisadores para "as utilizações mais condizentes ao seu objeto de pesquisa e aos múltiplos desdobramentos que o texto verbal, o texto visual e a intertextualidade conseguem admitir" (Leite, 1999, p. 114). Para chegar a tal conclusão, Mirian Moreira Leite demonstra que o tempo e o processo de conhecimento que a leitura envolve não podem ser adequadamente expressos em representações alicerçadas na imagem figurativa. Em contrapartida, as imagens podem bem representar as dimensões espaciais por privilegiar as formas sensíveis, as quais são adversas às formas já definidas em termos verbais e à possibilidade de abstração conceitual verbal.

As diferentes ferramentas expressivas subsidiárias do processo de construção de representações etnográficas trazem para o debate uma questão metodológica referente aos limites que as distintas opções narrativas apresentam ao serem postas em relação ao objeto de estudo que devem abarcar. Narrar através da escrita deixa de ser a única via de exposição e desenvolvimento do conhecimento antropológico, no sentido de que a escolha da forma narrativa passa a estar associada às características do objeto de estudo (ou o sentido inverso). Escolha que deve ser justificada de acordo com a capacidade do suporte narrativo para representar as dimensões interpretativas da realidade problematizada.

David MacDougall (1998), mesmo apresentando claramente uma preferência pelas imagens, demarca algumas especificidades distintivas entre o texto e a imagem. Segundo o autor, tanto a escrita quanto a imagem trazem as marcas das suas condições de produção, remetendo, assim, às mediações que as conformaram. Também, ambas podem abarcar o geral e o particular, todavia, de diferentes formas. $\mathrm{Na}$ escrita as exoticidades são isoladas por serem identificadas enquanto dados significativos, porém destituídas do contexto familiar em que estão inseridas na medida em que as familiaridades são postas em um segundo plano de importância. 
Ainda, na interpretação escrita, os detalhes das instâncias narradas não são abarcados na sua totalidade, visto que a estas são aplicados formatos mais facilmente assimilados. Isto ocorre porque a descrição através da escrita científica está presa ao código linguístico, apresentando dificuldades de tratar o que vai além do verbal. Portanto, há uma tendência na escrita pela categorização, que em certa medida generaliza os detalhes e, na ausência de uma descrição que trate as peculiaridades desses detalhes e as suas continuidades, o visível e o físico acabam obscurecidos. Por outro lado, através das imagens não é possível desenvolver categorizações, como $O$ Gaúcho, por exemplo, a não ser que um texto explicativo acompanhe a imagem ou anteceda a narrativa.

Nessa tensão entre escrita e imagem, se pelo viés da escrita é possível trazer a categoria de pessoa ou grupo, pelo prisma da imagem o fenômeno humano é apresentado. De modo geral, as imagens apresentam as continuidades físicas do mundo, uma vez que não há a discriminação dos detalhes. Por conseguinte, as imagens sempre trazem o geral em que o particular insere-se, assim como as suas continuidades. Desse ponto de vista, nas imagens as exoticidades apresentam-se envolvidas pelas familiaridades, congruência que a escrita não tem comportado. Na expressão visual as relações entre os sujeitos e sua inserção na dimensão espacial são apresentadas com mais eficácia se comparado ao texto escrito. Contudo, as imagens permitem visualizar que há algo em jogo nessas relações, mas não são suficientes para tornar compreensível as regras daquilo que é negociado. Porém isso não significa que não possam trazer conceitos, pois através das imagens são expressas as dimensões da vida que não conseguimos verbalizar de modo apropriado, mas que simbolizam como se fossem um não-dito na performance que colocam as expressões em movimentos (pensando a partir das teorias da Antropologia da Experiência). Diante dessas questões, MacDougall (2005) chama atenção para o fato de a antropologia visual tratar de elementos situados no campo da antropologia performativa. Sobre isso diz o autor:

Deve-se enfatizar que a antropologia visual é, em grande parte, uma antropologia performativa. É difícil concebe-la, tal qual a antropologia escrita faz, uma "tradução" da cultura que resultará em uma série de afirmações prepositivas. Referese, ao contrário, à apresentação dos objetos e à reconstituição das experiências no mundo (Macdougall, 2005, p. 28). 
Pontuando essas evidências e privilegiando a narrativa imagética, MacDougall identifica que a imagem:

Stresses social agency and more widely recognizable patterns of social interaction. I refer here to expression of pleasure or displeasure, the way in which people move and inhabit their environment, their uses of space, common skills in making things (Macdougall, 1998, p. 256) ${ }^{7}$.

Visual representation easily expresses external, behavioral features of emotion and visual clues to identity, that written descriptions express only with some difficulty. Thus, images of people on a street may revel continuities across subcultural boundaries (of dress, gesture, association) that are missed or masked in written accounts (Macdougall, 1998, p. 257) ${ }^{8}$.

MacDougall (1998), ao estabelecer essa discussão demarca as potencialidades e os limites do aporte da escrita científica e da imagem figurativa na construção da representação etnográfica, demonstrando essencialmente os conteúdos que cada forma narrativa privilegia. De acordo com MacDougall (2005), já haveria quatro áreas em que a atuação da antropologia visual seria pertinente: o topográfico (o lugar e o espaço e as culturas que neles são negociadas), o temporal (aspectos mais amplos ligados a temas históricos), o corporal (performances da vida cotidiana) e o pessoal (cultura e personalidade, por exemplo, papéis sociais e hierarquias).

Retomando os pensamentos de Mirian Moreira Leite (1999), a aplicação do texto visual sobre a urbanização satisfaz a abordagem das suas dimensões espaciais. Complementando com os argumentos de MacDougall (2005) articulados à visão de Michel de Certeau (1994), penso que também alcança a dimensão do lugar praticado e das negociações simbólicas que se desenrolam no espaço e no tempo das relações sociais. Considerando que o propósito já enunciado dessa discussão reside em uma reflexão acerca da possibilidade de expressão do conceito de Atratividade do Espaço Urbano por meio de uma narrativa imagética, a primeira evidência argumentativa para a adequação da construção desse conceito através de imagens acaba de ser apresentada: o espaço é um objeto de estudo apropriado à interpretações situada dentro do campo da

\footnotetext{
${ }^{7}$ Enfatiza a dimensão social e os padrões de interação social mais largamente reconhecíveis. Me refiro aqui à expressão de prazer ou desprazer, à forma como as pessoas se movimentam e habitam seu entorno, seus usos do espaço, habilidades comuns em fazer coisas [tradução].

8 A representação visual facilmente expressa a exterioridade comportamental, características emocionais e instâncias visuais a serem identificadas, que descrições escritas expressam somente com alguma dificuldade. Então, imagens de pessoas na rua pode revelar continuidades através dos limites culturais (vestimenta, gestos, associação) que são perdidas ou mascaradas nos limites da escrita [tradução]
} 
Antropologia Visual (ou vice-versa), tanto no que tange às suas formas espaciais (fixos) quantos ao movimento que habita e reproduz suas formas (fluxos).

O conceito de atratividade está alicerçado na generalidade da condição do espaço urbano complexo e no universo empírico da cidade de Buenos Aires. Se a imagem traz mais a condição humana do que a possibilidade de categorização do sujeito (MacDougall, 1998), a imagem pode trazer a condição do espaço urbano mais do que uma leitura categórica das especificidades culturais do local. Se a imagem traz a unicidade do sujeito na sua condição humana, mais do que a sua generalização através da categorização (MacDougall, 1998), a imagem pode trazer o conceito de atratividade do espaço urbano na unicidade empírica de Buenos Aires. O importante no conceito de atratividade não é descrever o universo simbólico negociado, mas sim evidenciar que há no movimento que a imagem denuncia sentidos performados ${ }^{9}$ nas práticas realizadas nas dimensões do espaço urbano.

Assim, ao mesmo tempo em que o conceito de atratividade do espaço urbano traz o geral e o abstrato da condição urbana, ela materializa-se nas formas empíricas do local (formas materiais / formas de praticar o espaço - o físico e a disposição dos corpos no movimento / as relações e os sentidos performados através das práticas - a experiência urbana de Buenos Aires). Portanto, o conceito de atratividade do espaço urbano tem no seu cerne uma dimensão visual geral presente nos elementos que compõe os aspectos físicos do espaço (a materialidade dos fixos envolvida pelas disposições corporais do movimento efêmero que cruza o espaço) e igualmente carrega uma dimensão específica que adentra a cidade nas performances dos sujeitos e nos lugares praticados (as múltiplas formas de habitar a cidade), elementos que compõem os ares de Buenos Aires.

A mediação que envolve a produção de imagens é constituída por toda discussão teórica até aqui realizada, a qual orienta as formas de recortar a realidade e que, no seu compartilhamento, facilitará a compreensão das imagens - "se fotografar é dar a ver, fotografar é também, a priori, uma forma de pensar e olhar o real" (Achutti, p. 99). É nesse sentido que a imagem pode trazer altos níveis de abstração teórica, porém transcendendo a sua representação escrita na medida em que articula o campo teórico

\footnotetext{
${ }^{9}$ Pensando a partir das teorias da Antropologia da Experiência e do conceito de prática discursiva enquanto toda prática atribuída de sentido, muitas vezes um não-dito, seja porque não é sabido ou porque há um gap (expressão de Bruner para evidenciar a insuficiência do código linguístico) entre o sentido e a linguagem.
} 
com as formas sensíveis da vida.

O que parece interessante para a antropologia é a utilização da fotografia para trabalhar além das aparências, pois, no que diz respeito à pesquisa, o que mais conta não é o simples registro de fatos, mas o que está fora do campo da visão, a construção do sentido graças à imagem; isso para tornar-se um meio de restituição, uma outra forma de narrar nosso olhar sobre o Outro. É o que caracteriza a fotoetnografia, a fotografia como escritura por inteiro, quando se pára de recorrer às palavras para se deixar levar em uma viagem visual reveladora. Abrigando o inefável que igualmente encerra conhecimento e sentido (Achutti, 2004, p. 87).

Portanto, a atratividade do espaço urbano será construída em uma narrativa visual sobre o caso de Buenos Aires. Essa experiência prática não pode ser desprovida de uma reflexão. Tendo em vista que a fotografia foi escolhida como meio narrativo, para realizar essa produção Achutti (2004) chama atenção para a elaboração de um planejamento prévio (um método) e para a necessidade do domínio técnico do equipamento de modo que as imagens possam vir a constituir nas suas inter-relações uma narrativa.

Sobre o domínio da técnica, Achutti centra-se no enquadramento (escolha dos planos presentes no recorte), assim como na abertura do diafragma e as diferentes profundidades de campo produzidas. Questões que remetem ao enfoque dado ao objeto central da imagem, fazendo refletir sobre em que medida esse objeto focado dialoga com os demais planos, logo, intervindo na escolha da profundidade de campo a ser produzida através do domínio das diferentes aberturas do diafragma e na dimensão do enquadramento aplicado pelo fotógrafo. Ainda, no que tange o âmbito do enquadramento e a profundidade de campo, o tipo de objetiva também representa um recurso técnico, visto que uma grande-angular propicia uma abrangência maior do campo, ao passo que uma teleobjetiva fecha o enquadramento.

Além das escolhas e dos domínios técnicos o pesquisador deve saber olhar. Somente a prática permite conjugar esses dois domínios. Através da prática a operação técnica gradativamente demandará menos tempo de reflexão, visto que o fotógrafopesquisador passa a se familiarizar com as operações práticas podendo fixar suas preocupações na constituição da imagem, a qual não deixa de estar intrinsecamente ligada ao domínio técnico. O que ocorre é uma "naturalização" técnica que transforma o equipamento em uma extensão do olhar - "o fotógrafo se distancia da técnica para que seu olhar possa mergulhar no universo que constitui o objeto de suas pesquisas. De fato, a falta de prática ou um certo fetichismo por seu instrumento de trabalho poderia leva-lo 
a realizar uma obra superficial” (Achutti, 2004, p. 113). Já esmiuçadas as questões técnicas, sobre o planejamento Achutti diz:

Se desde o princípio do trabalho de campo o pesquisador-fotógrafo não tiver em mente a paginação final (ou montagem de exposição fotográfica, conforme o caso), o resultado de seu trabalho sofrerá dessa falta de planejamento, pois uma narrativa visual que pretenda utilizar a fotografia deve ser fruto de um longo processo de construção, a construção de uma descrição visual. As fotografias no final devem formar um todo (2004, p. 108).

De acordo com Achutti (2004), o pesquisador deve inicialmente ir a campo para observar, entrar em contato com as pessoas e impregnar-se daquele universo. Assim, o bloco de notas não deve ser abandonado, mesmo quando a produção de imagens iniciar. Depois do mapeamento do campo de estudo, o pesquisador pode criar um roteiro para orientar o início da produção das imagens. Ainda, o fotógrafopesquisador deve revelar as imagens durante o processo de produção para que possa voltar diversas vezes ao campo em busca de outras imagens complementares ou substitutas.

Seguindo um processo de seleção permanente, o fotoetnógrafo deverá, portanto, proceder à organização dos dados e das fotos de forma a constituir um todo. A medida que sua pesquisa avança, ele vai substituir algumas delas, trocar outras de lugar, acrescentar novas, tendo como objetivo final a coerência de um conjunto de imagens. As fotos que não foram bem-sucedidas poderão ser substituídas (Achutti, 2004, p. 117).

Todo este processo será orientado pela técnica da Etnografia de Rua, proposta por Cornelia Eckert e Ana Luiza Carvalho da Rocha, a qual "consiste na exploração dos espaços urbanos a serem investigados através de caminhadas «sem destino fixo» nos seus territórios" (2001, p. 6). Trata-se de uma técnica de imersão na vida cotidiana que se desenrola no espaço pesquisado, desafiando o antropólogo a vivenciar a cidade através das múltiplas dimensões que a complexificam: espacialidades, temporalidades, ambiências, caminhos, ruídos, cheiros, cores, direções, movimentos e paisagens. Assim, os deslocamentos frequentes pelo espaço demarcado, juntamente com a observação sistemática, possibilita a inserção do pesquisador na dinâmica da vida cotidiana, permitindo que esse identifique e descreva, a partir dos fragmentos coletados durante esse processo, os cenários, os personagens constantes, a rotina e os imprevistos, as tensões e conflitos, buscando, então, suas significações (Eckert; Rocha, 2001). 
Assim, o ato simples de andar torna-se estratégia para igualmente interagir com a população com as quais cruzamos nas ruas. Habitués, frequentadores, ou simples passantes, todos eles convidam ao etnógrafo a perfilar personagens, descrever ações e estilos da vida a partir de suas performances cotidianas (Eckert; Rocha, 2001, p. 7).

Essa técnica de pesquisa vem a privilegiar a constituição do conceito de atratividade do espaço urbano devido ao fato de o pesquisador colocar-se na experiência urbana de forma similar à experiência do turista em contextos urbanos: através de caminhadas sem compromissos, o flâneur. Evidentemente, a reflexão empregada pelo antropólogo diverge do olhar do turista e a temporalidade da experiência turística é reduzida em relação à experiência antropológica, além de ser, por vezes, controlada pelos roteiros turísticos. Contudo, a atratividade revela-se nesse andar pela cidade, diversas vezes mencionada pelos entrevistados como algo agradável; levando à caracterização da cidade: "Buenos Aires é uma cidade boa para caminhar, é plana".

Durante essas caminhadas, interações, observações, o antropólogo deve ser capaz de identificar as instâncias significativas para realizar uma interpretação da vida social do espaço (no seu sentido complexo) que se propôs a analisar. Considerando que em uma rua apenas, por exemplo, é possível encontrar diversos fragmentos merecedores do olhar mais atento do pesquisador, algumas escolhas devem ser realizadas, conforme relata Patrícia Rodolpho (2001) ao se deparar com a multiplicidade de elementos culturais significativos presentes da Rua da Praia, oficialmente chamada de Rua dos Andradas, em Porto Alegre.

A realização da Etnografia de Rua, que neste caso contempla o espaço da Rua da Praia, mais especificamente de três de suas quadras. Inicialmente, mapeia-se a rua na sua totalidade, mas a atividade etnográfica mostrou que cada quadra ou cruzamento de rua oferece uma infinidade de elementos e circunstâncias passíveis de serem exploradas pelo pesquisador (Rodolpho, 2001, p. 3).

Em minha prática, procurei percorrer, na primeira semana, toda a área central representada como turística nos mapas analisados com a finalidade de demarcar os locais aos quais me deteria. Sempre ia a pé e voltava com algum meio de transporte, ou vice-versa Determinei alguns espaços-chave, dentre eles a Plaza de Mayo, os bosques de Palermo, a Calle Florida e o bairro de San Telmo, onde residi por quase quatro 
meses. Diante de tais locais e de algumas imagens, comecei a refletir sobre a construção e estruturação da narrativa imagética, pois deveria pensar na composição e, caso fosse necessário, deveria retornar aos locais para coletar imagens para a composição final. Em um primeiro momento o fio condutor passou a ser o percurso que interligava os espaços estudados. Todavia, no decorrer da experiência antropológica, descobri que as instâncias significativas reincidiam em diferentes momentos e lugares. Dessa forma, busquei na pesquisa, referida no início desse artigo, compor uma narrativa que problematizasse não apenas os espaços, mas na qual fossem postas em evidência as instâncias significativas que circulam pela cidade através do movimento urbano, estando presente em diversos lugares, tempos e camadas sociais. Uma narrativa que falasse do movimento da atratividade de Buenos Aires.

Para finalizar, abaixo consta uma breve narrativa sobre conceitos desenvolvidos por meio da escrita que representam as temporalidades urbanas, suas dinâmicas e o contraponto entre essa complexidade cotidiana (Atratividades) e os Atrativos Turístivos. Em parte, assim se sustenta o argumento de que a dinâmica urbana pode ser representada em imagens, bem como sua atratividade, mas se evidencia o referencial teórico literário que sustenta esses recortes e escolhas. Ainda fica a dúvida sobre uma fotoetnografia circunscrita por teorias verbais ou por uma etnografia escrita mergulhada em transgressão poética da palavra para alcançar as imagens das formas sensíveis da vida. 


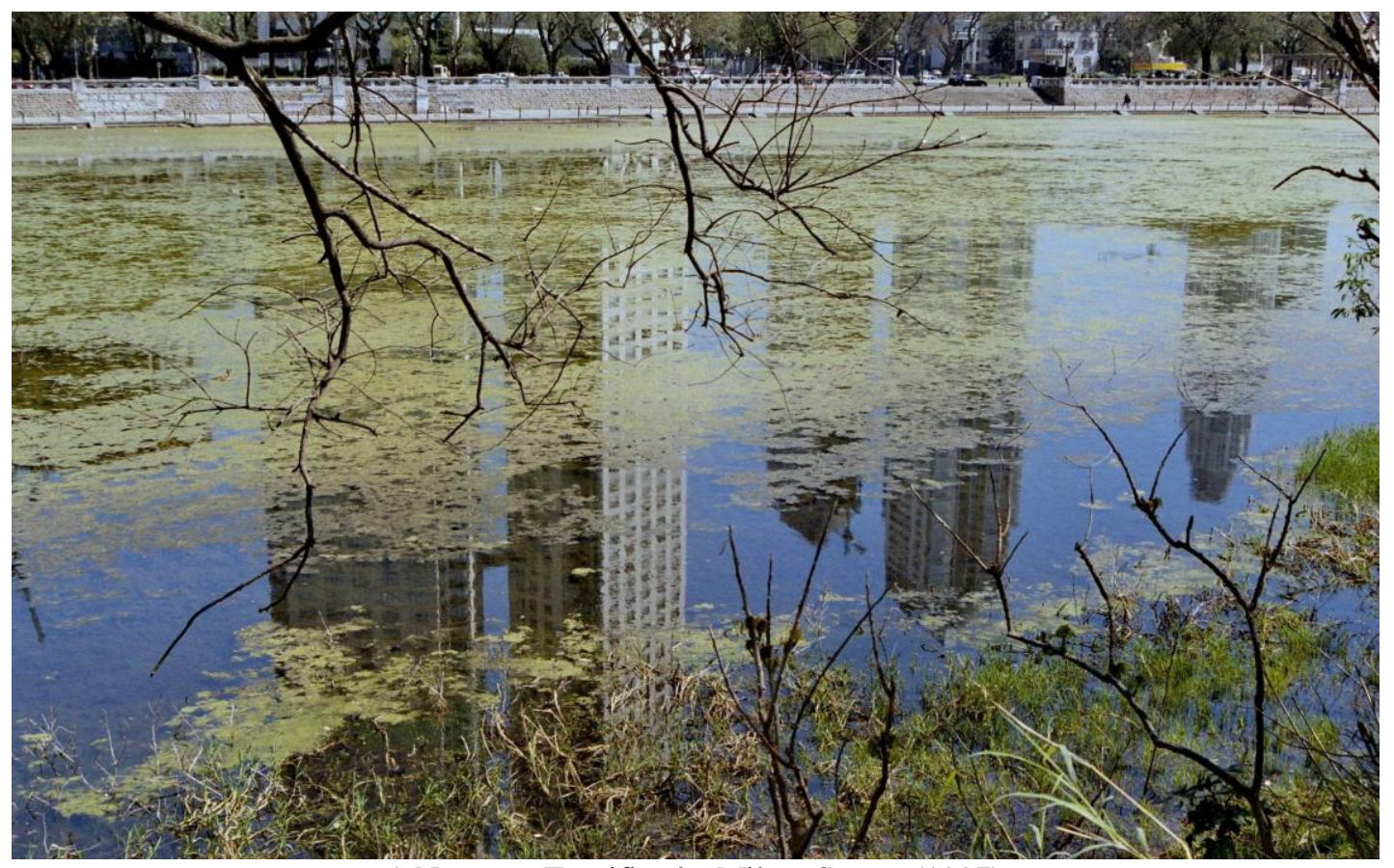

A Natureza Tecnificada, Milton Santos (1997).

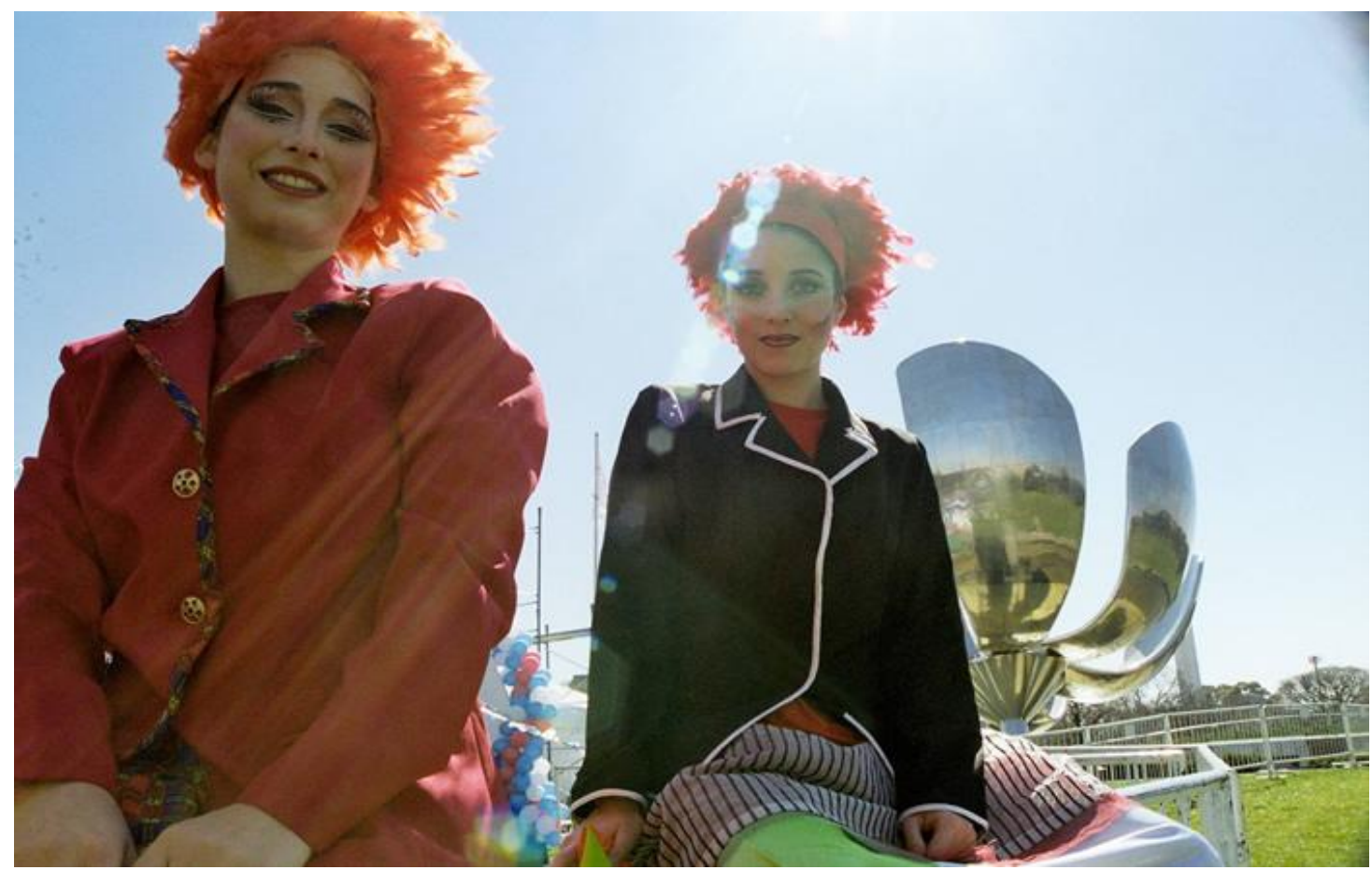

Tempos do Espaço Urbano: a atratividade e o atrativo turístico. 


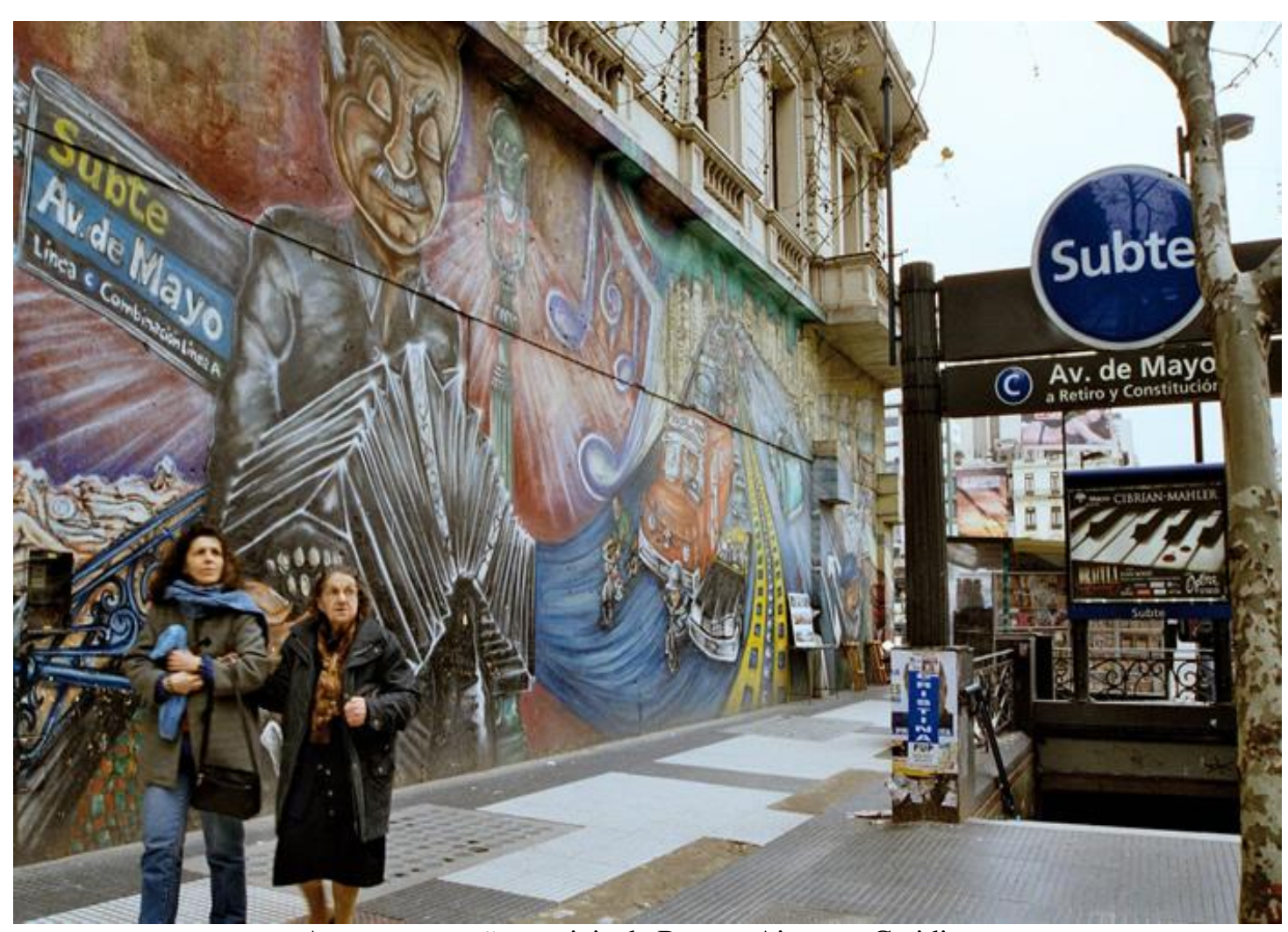

As representações sociais de Buenos Aires e o Cotidiano.

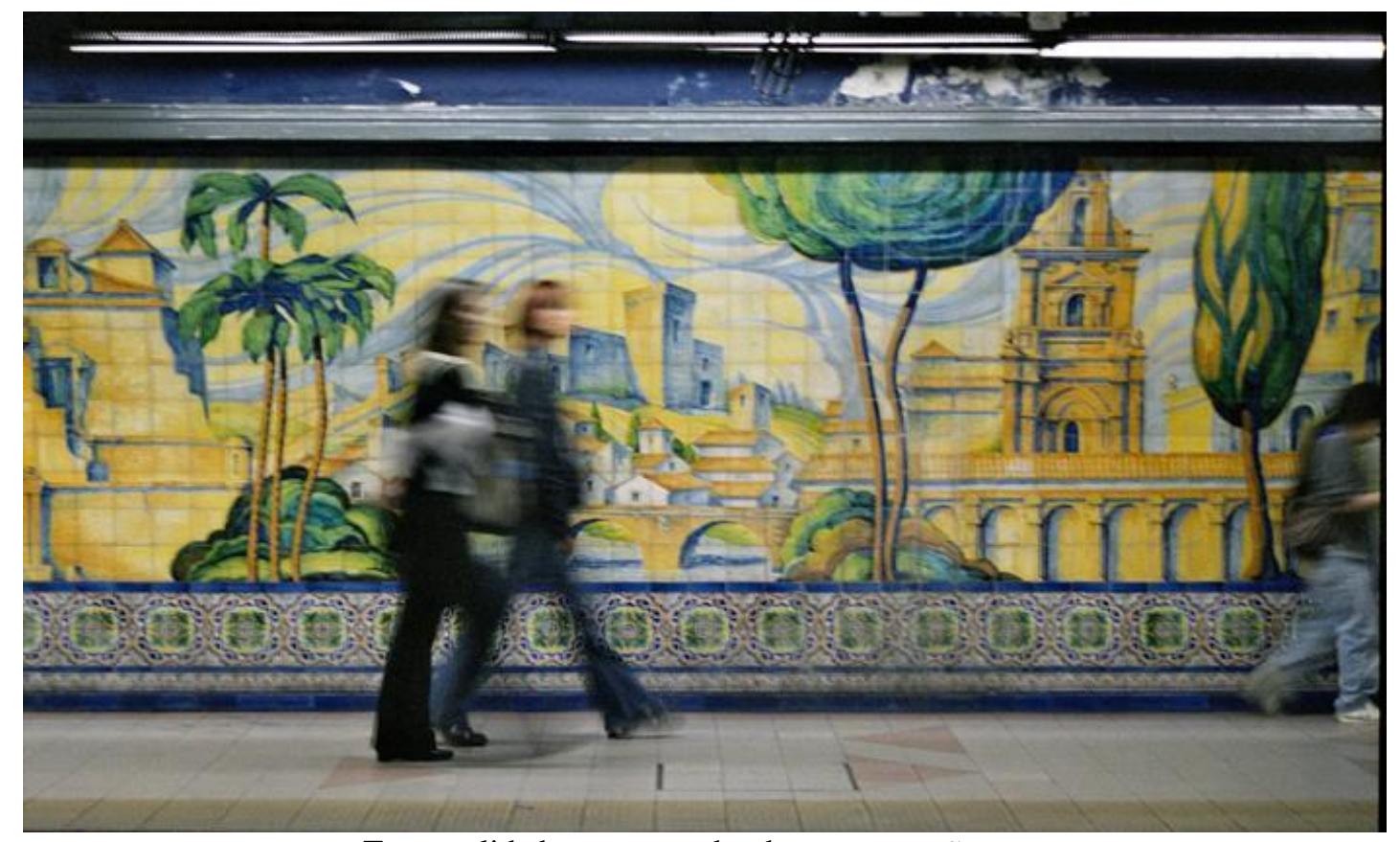

Temporalidades, arte e poder de representação. 


\section{Referências}

ACHUTTI, Luiz Eduardo Robinson. Fotoetnografia da Biblioteca Jardim. Porto Alegre: Editora da UFRGS, 2004.

ACHUTTI, Luiz Eduardo Robinson. Fotos e palavras, do campo aos livros. Revista STUDIUM, nº12, 2000. Disponível em <www.studium.iar.unicamp.br/12/1.html> Acesso em jun. 2007.

BARRIOS, Sonia. A Produção do Espaço. In: SOUZA, Maria Adélia A. de; SANTOS, Milton (orgs). A construção do Espaço. São Paulo: Nobel, 1986, p. 1-24.

BERGER, Peter; LUCKMANN, Thomas. A Construção Social da Realidade: Tratado de Sociologia do Conhecimento. Petrópolis: Vozes, 1998.

BITTENCOUTR, Luciana Aguiar. Algumas considerações sobre o uso da imagem fotográfica na pesquisa antropológica. In: FELDMAN-BIANCO, Bela; LEITE, Míriam L. Moreira (orgs). Desafios da imagem: fotografia, iconografia e vídeo nas ciências sociais. Campinas: Papirus, 1998, p.197-212.

BRANDÃO, Helena Hathsue Nagamine. Introdução à análise do discurso. 2. ed. Campinas, São Paulo: UNICAMP, 2004.

BRUNER, Edward M. Experience and its expressions. In: BRUNER. Edward M.; TURNER, Victor W. The anthropology of experience. Chicago, EUA: University Of Illinois Press, 1986. p. 03-30.

CARLOS, Ana Fani Alessandri. Espaço-tempo na Metrópole: a fragmentação da vida cotidiana. São Paulo: Contexto, 2001.

CASTROGIOVANNI, Antonio Carlos. A Geografia do Espaço turístico, como Construção Complexa da Comunicação. 2004. Tese (Doutorado em Comunicação Social), PUCRS, FAMECOS, Porto Alegre, 2004.

CASTROGIOVANNI, Antonio Carlos. Turismo e ordenação no espaço urbano. In: (org.). Turismo Urbano. São Paulo: Contexto, 2001, p. 23-32.

CERTEAU, Michel de; GIARD, Luce; MAYOL, Pierre. A invenção do cotidiano. 11. ed. Petrópolis: Vozes, 1994.

DAMATTA, Roberto. Oficio do Etnólogo, ou como ter o Antropological Blues. In. NUNES, Edson de Oliveira (org). A Aventura Sociológica: objetividade, paixão, improviso e método na pesquisa social. Rio de Janeiro: Zahar, 1978, p. 23-35.

DAMATTA, Roberto. Relativizando: uma introdução à antropologia social. Rio de Janeiro: Rocco, 2000.

DESAULNIERS, Julieta Beatriz Ramos. Tempo: uma categoria, várias abordagens. Veritas, Porto Alegre, v. 41, n. 162, p. 315-321, jun. 1996.

DUVEEN, Gerard. Introdução: o poder das ideias. In: MOSCOVICI, Serge. Representações Sociais: investigações em psicologia social. 3. ed. Petrópolis: Vozes, 2003, p.07-28.

ECKERT, Cornelia; ROCHA, Ana Luiza Carvalho da. Etnografia de Rua: estudo de antropologia urbana. Iluminuras, Porto Alegre, n.44, 2001. Disponível em: <www.estacaoportoalegre.ufrgs.br/html/producao/iluminuras/iluminuras.htm> Acesso em: out. 2006.

ECKERT, Cornelia; GODOLPHIM, Nuno; RODOLPHO, Adriane; ROSA, Rogério. A experiência do núcleo de antropologia visual - UFRGS. Horizontes Antropológicos, Porto Alegre, ano 1, n. 2, p. 221-230, jul.-set. 1995.

FERREIRA, Alvaro Henrique de Souza. Espaço, Tempo, Ciberespaço: Produzindo Novas Temporalidades e Especialidades. In: CARLOS, Ana Fani Alessandri; LEMOS, Amália Inês Geraiges (orgs). Dilemas Urbanos: Novas Abordagens Sobre a Cidade. São Paulo: Contexto, 2003, p. 119-128.

GAYER, Priscila. Adentrando Buenos Aires: do movimento a cristalização. Revista Virtual Partes, ago.2007. Disponível em: <www.partes.com.br/turismo/adentrando.asp> Acesso em: ago.2007-a.

GAYER, P. Um Lugar Metodológico para os Estudos dos Processos Culturais no Fenômeno do Turismo: a Experiência Turística sob a Perspectiva da Antropologia da Experiência. In: VII 
RAM - Reunião de Antropologia do Mercosul, Desafios Antropológicos, 2007, Porto Alegre. Anais, 2007-b.

GEERTZ, Clifford. A interpretação das culturas. Rio de Janeiro: LTC, 1989.

GEERTZ, Clifford. Making Experience, Authoring Selves. In: BRUNER, Edward M.; TURNER, Victor W. The anthropology of experience. Chicago, EUA: University Of Illinois Press, 1986, p. 373-380.

GOLDEMBERG, Mirian. A arte de pesquisar: como fazer pesquisa qualitativa em ciências sociais. Rio de Janeiro: Record, 1999.

GRIMSHAW, Anna. The ethnographer's eye: Ways of seeing in modern Anthropology. Cambridge, Cambridge University Press, 2003.

LAKATOS, Eva; MARCONI, Marina de Andrade. Fundamentos de Metodologia Científica. 4. ed. São Paulo: Atlas, 2001.

LAPLANTINE, François. Aprender Antropologia. São Paulo: Brasiliense, 2000.

LARAIA, Roque de Barros. Cultura: um conceito antropológico. 16. ed. Rio de Janeiro: J. Zahar, 2003.

LUCHIARI, M. Tereza de C. P. Urbanização Turística: um novo nexo entre o lugar e o mundo. In. SERRAN, Celia, BRUHNS, Heloísa T. LUCHIARI, M. Tereza de C. P. (orgs). Olhares contemporâneos sobre o Turismo. Campinas, Papirus, 2000, p. 105-130

MACDOUGALL, David. Novos princípios da antropologia visual. Cadernos de Antropologia e Imagem. Rio de Janeiro, UERJ, v. 21, n. 02, 10 anos (1995-2005) p.20-31, 2005.

MacDOUGALL, David. Transcultural Cinema. Princeton, New Jersey: Princeton University Press, 1998.

MacDOUGALL, David. The corporeal image: Film, ethnography and the senses. Princeton, New Jersey: Princeton University Press, 2006.

MAFFESOLI, Michel. O Imaginário é uma Realidade. Revista Famecos, Porto Alegre, n. 15, p. 74-81, ago. 2001.

LEITE, Miriam Moreira. O opaco e a transparência do texto visual. In: Eckert, Cornelia; MonteMor, Patrícia (orgs). Imagem em foco, novas perspectivas em antropologia. Porto Alegre: Editora da UFRGS, 1999, p. 105-113.

MORIN, Edgar. $O$ Método 4. 3. ed. Porto Alegre: Sulina, 2002.

MOSCOVICI, Serge. A representação social da psicanálise. Rio de Janeiro: Zahar, 1978.

MOSCOVICI, Serge. Representações sociais: investigações em psicologia social. 3. ed. Petrópolis, RJ: Vozes, 2003.

NUNES, José Horta. O espaço urbano: a "rua" e o sentido público. In: ORLANDI, Eni Pulcinelli. Cidade atravessada: os sentidos públicos no espaço urbano. Campinas: Pontes, 2001, p. 101-110.

ORLANDI, Eni Pulcinelli. Análise de discurso: princípios \& procedimentos. 5. ed. Campinas: Pontes, 2003.

ORLANDI, Eni Pulcinelli. As formas do silêncio: no movimento dos sentidos. 2. ed. Campinas: editora da UNICAMP, 1993.

ORLANDI, Eni Pulcinelli. Cidade dos sentidos. Campinas: Pontes, 2004.

ORLANDI, Eni Pulcinelli. Apresentação: cidade atravessada. In: ___ Cidade atravessada: os sentidos públicos no espaço urbano. Campinas: Pontes, 2001, p. 7-8.

ORLANDI, Eni Pulcinelli. Tralhas e troços: o flagrante urbano. In: __ Cidade atravessada: os sentidos públicos no espaço urbano. Campinas: Pontes, 2001, p. 11-24.

PAIVA, Eduardo França. História \& Imagens. 2. ed. Belo Horizonte: Autêntica, 2004.

PECHEUX, Michel. O discurso: estrutura ou acontecimento. 2. ed. Campinas: Pontes, 1997.

PESAVENTO, Sandra Jatahy. A Construção de uma Porto Alegre imaginária: uma cidade entre a memória e a história. In: GRIJÓ, Luiz Alberto; KÜHN, Fábio; GUAZZELLI, Cesar Augusto Barcellos; NEUMANN, Eduardo Santos (orgs). Capítulos de história do Rio Grande do Sul. Porto Alegre: Editora da UFRGS, 2004, p. 179-208.

PESAVENTO, Sandra Jatahy. Nação e Região: Diálogos do "Mesmo" e do "Outro". In: História Cultural: Experiências de Pesquisa. Porto Alegre: UFRGS, 2003, p. 209-242. 
RODOLPHO, Patrícia. Encontrando imagens na e da Rua da Praia: problemas e descobertas de uma etnografia urbana. Iluminuras, Porto Alegre, n. 26, 2001. Disponível em: <www.estacaoportoalegre.ufrgs.br/html/producao/iluminuras/iluminuras.htm> Acesso em: out. 2006.

SALGUEIRO, Teresa Barata. Espacialidades e Temporalidades Urbanas. In. CARLOS, Ana Fani A; LEMOS, Amália (orgs). Dilemas Urbanos: novas abordagens sobre a cidade. São Paulo: Contexto, 2003, p. 99-104.

SANTOS, Milton. A Natureza do Espaço: Técnica e Tempo, Razão e Emoção. São Paulo: Hucitec, 1997.

SANTOS, Milton. Espaço e Sociedade. Petrópolis: Vozes, 1979.

SERPA, Angelo. O espaço público na cidade contemporânea. São Paulo: Contexto, 2007.

SUERTEGARAY, Dirce Maria Antunes. Espaço Geográfico Uno E Múltiplo. Scripta Nova: Revista Electrónica de Geografía y Ciencias Sociales, Universidad de Barcelona, n. 93, jul. 2001. Disponível em: <www.ub.es/geocrit/sn-93.htm> Acesso em: 21 abr. 2006.

Recebido em: 22/03/2015

Aprovado em: 20/05/2015 